\title{
Unexpected Precipitation of a Re-Rich Phase in Single Crystal Superalloy CMSX-4 during Thermal Exposure
}

\author{
Kuiyu Cheng, ${ }^{1,2}$ ChangYong Jo, ${ }^{2}$ DooHyun Kim, ${ }^{3}$ Tao Jin, ${ }^{1}$ and Zhuangqi Hu1 \\ ${ }^{1}$ Superalloy Division, Institute of Metal Research, Chinese Academy of Sciences, 72 Wenhua Road, Shenyang 110016, China \\ ${ }^{2}$ High Temperature Materials Group, KIMS, 531 Changwondaero, Changwon 641-010, Republic of Korea \\ ${ }^{3}$ Materials Test and Characterization Group, KIMS, 531 Changwondaero, Changwon 641-010, Republic of Korea
}

Correspondence should be addressed to Kuiyu Cheng, kuiyucheng@hotmail.com

Received 12 September 2011; Accepted 19 October 2011

Academic Editor: Hao Chen

Copyright (c) 2012 Kuiyu Cheng et al. This is an open access article distributed under the Creative Commons Attribution License, which permits unrestricted use, distribution, and reproduction in any medium, provided the original work is properly cited.

\begin{abstract}
A Re-rich phase (up to $85.40 \%$ wt.Re) was occasionally found in a single crystal superalloy during thermal exposure. Interestingly, this phase is located in front of the dendrite periphery in the interdendritic region, while the Re is segregated in the dendrite core. Formation of this phase was suggested to relate to the unusual accumulation of the Re resulting from the uneven diffusion process of Re. Appearance of this phase may imply the preference of forming Re-Re atomic bond in the superalloys.
\end{abstract}

\section{Introduction}

The beneficial effect of Re on the high temperature properties of single-crystal nickel-based superalloys has resulted in a steady increase in the levels of Re used in these alloys $[1,2]$. As a result, role and behavior of Re in superalloys have been drawing increasing attention over recent years [3-16]. Rhenium could significantly reduce the $\gamma^{\prime}$ coarsening rate [3] and is beneficial in producing alloys with small negative lattice misfit parameters [4]. In addition, atom probe investigations of Re-containing superalloys have reported both clustering of Re in the $\gamma$ phase $[5,6]$ and pileup of Re at the $\gamma / \gamma^{\prime}$ interface $[7,8]$. Therefore, the position and the existing way of Re plays a significant role in mechanical properties of the superalloys. However, the mechanisms for Re acting in superalloys are not well established yet.

In this study, a Re-rich phase (up to $85.40 \%$ wt.Re) was unexpectedly found in the well-known single crystal superalloy CMSX-4 during thermal exposure. Interestingly, this phase is located in front of the dendrite periphery in the interdendritic region, while the Re is segregated in the dendrite core. The possible formation mechanism of this phase was discussed as well as its significance to the superalloys in the present study. It is thought that the present study is helpful for understanding the particular role and behavior of Re in Nickel-base superalloys.

\section{Experimental Procedure}

The mother alloy of single crystal alloy CMSX-4 used for the present work was supplied by CMSX Company. The casting method and nominal composition of the single crystal bars have been given in previous work [9]. The single crystal bars were sliced to small pieces $(12 \mathrm{~mm} \times \Phi 14 \mathrm{~mm})$ and were given a standard heat treatment (heat to $1260^{\circ} \mathrm{C}$ at $360^{\circ} \mathrm{C} / \mathrm{h}$, hold $0.2 \mathrm{~h}$, heat to $1288^{\circ} \mathrm{C}$ at $30^{\circ} \mathrm{C} / \mathrm{h}$ and heat to $1320^{\circ} \mathrm{C}$ at $2^{\circ} \mathrm{C} / \mathrm{h}$, hold $2 \mathrm{~h}+\mathrm{AC} ; 1140^{\circ} \mathrm{C} / 2 \mathrm{~h}+\mathrm{AC} ; 870^{\circ} \mathrm{C} / 20 \mathrm{~h}+\mathrm{AC}$ ). Then, the samples were thermally exposed at $950^{\circ} \mathrm{C}$ between 500 5000 hours. The microstructures were carefully examined by the scanning electron microscope (SEM) with an energy dispersive X-ray analysis (EDS) accessory. It should be pointed out that only the observations made on the samples which show the unexpected formation of the Re-rich phase will be presented in this paper.

The composition mapping of Re was carried out with a Shimadzu mode electron probe microanalysis (EPMA) machine to examine and analyze the Re distribution before and after standard heat treatment according to the dendrite structure.

\section{Result}

3.1. Appearance of the Re-Rich Phase. The only phases occurred in the CMSX-4 specimens before or after standard 
TABLE 1: Chemical composition of the Re-rich phase in present study (wt.\%).

\begin{tabular}{lccccc}
\hline $\mathrm{Al}$ & $\mathrm{Cr}$ & $\mathrm{Co}$ & $\mathrm{Ni}$ & $\mathrm{W}$ & $\mathrm{Re}$ \\
\hline 1.08 & 1.89 & 1.05 & 10.15 & 0.43 & 85.40 \\
\hline
\end{tabular}

heat treatment are $\gamma, \gamma^{\prime}$, and $\gamma / \gamma^{\prime}$ eutectics. The detail of the specimen after standard heat treatment can be found in previous work [9]. Figure 1 shows the microstructure and EDS analysis of the specimen after thermal exposure of 800 hours at $950^{\circ} \mathrm{C}$. As we can see, a bright phase was occasionally found in the backscattered electron image (Figure 1(a)), which indicates that this phase consists of high content of refractory alloying elements. Moreover, this phase presents faceted morphology and is distributed in front of the dendrite periphery in the interdendritic region, especially in the corners between the dendrite arms. The EDS analysis clearly proves that this phase is primarily composed of Re and a little Ni with minor of $\mathrm{Al}, \mathrm{Cr}, \mathrm{Co}$, and $\mathrm{W}$, most of which are $\gamma$ forming elements (Figure 1(c)). The detail of the composition obtained by EDS is given in Table 1. It can be seen that the content of Re (up to $85.40 \%$ wt.) is much higher than those of other elements.

In the specimens thermally exposed for 1000 hours, this Re-rich phase could be hardly found at low magnification, while at high magnification pieces of this phase were detected as shown in Figure 2. The morphology of this Re-rich phase is more regular with clearly pyramid facets in this condition. Furthermore, the phase distribution and composition are consistent with those in the condition of 800 hours exposure.

It should be pointed out that, although this phase was not found in the specimens with the shorter or longer exposure times, it is hard to say whether this phase formed or not in those conditions because of the much few amount. However, it at least demonstrates that this Re-rich phase mostly formed after approximate 800 hours during thermal exposure at $950^{\circ} \mathrm{C}$ and gradually disappeared with increasing the thermal exposure time. In addition, since the amount of this Re-rich phase is very low in the specimen, it is difficult to find an effective way to identify this phase such as selected diffraction pattern.

3.2. Re Distribution. As this phase is strongly rich in Re, the Re distribution in the specimens before and after the standard heat treatment was analyzed by EPMA mapping analysis. The mapping analysis is conducted on a scale of one dendrite structure as shown in Figure 3. The Re is strongly segregated in the dendrite core or in the center of the secondary arm in the as-cast condition (Figure 3(a)). After the standard heat treatment, most microsegregation of the Re was homogenized with unclear dendrite structure in the EPMA maps (Figure 3(b)). Inset shows the analyzed area in the standard heat-treated specimen. Moreover, it should be emphasized that as many as EPMA maps obtained from other fields of the examined as-cast and standard heat-treated specimens are consistent with that shown in Figure 3. No particular segregation of Re was detected in the corresponding region in which the Re-rich phase precipitated during following thermal exposure.

\section{Discussion}

4.1. Re-Rich Phase in Superalloy. The Re-rich phase is very unusual in superalloys. A Re-rich $\delta$-phase has been reported in as-cast and heat-treated Ni-Al-Re ternary alloys $[10,11]$ and later was found in variety of superalloys $[12,13]$. Composition of the Re-rich phase found in this study is of some difference to theirs, with lower Re content and higher $\mathrm{Ni}$. However, since Re and $\mathrm{Ni}$ are the main components in the Re-rich phase in this study (Table 1) and there is no other compound of Re and Ni according to the Ni-Re phase diagram [14], this Re-rich phase might be the Ni-oversaturated $\delta$-Re phase formed by the incomplete precipitation of the Re from the matrix during the thermal exposure. This could also explain the minor contents of $\mathrm{Al}, \mathrm{Cr}, \mathrm{Co}$, and $\mathrm{W}$ in this phase.

4.2. Possible Formation Mechanism of the Re-Rich Phase in CMSX-4. In this study, the alloy CMSX-4 used and other Re-containing alloys as well [13] have been melted once to make the initial ingots and again in the single crystal solidification process. Furthermore, this phase has displayed certain crystallographic morphology with matrix in the solid state as shown in Figure 2. Therefore, presence of this phase is unlikely due to insufficient time for dissolution of the initial Re additions to the alloy. Feng et al. have come up with two ways in which the Re-rich $\delta$-phase could form in their alloys: form in the interdendritic region by peritectic reaction during the solidification or form in the dendrite core during the aging heat treatment due to the strong segregation of Re there [13]. However, neither of them is applicable in present study, since this phase was not found in the as-cast condition and the Re is segregated in the dendrite core rather than in the area where this phase formed (Figure 3 ). It indicates that formation of this phase in CMSX-4 alloy was controlled by a distinct mechanism with those in Feng's study. It is proposed that this Re-rich phase here is possibly induced by unusual accumulation of Re during later thermal exposure.

It is well known that alloy elements have different preference of segregation in dendrite and interdendritic area which would lead to two cross-diffusion fluxes in elevated temperature: $\mathrm{W}, \mathrm{Re}, \mathrm{Cr}, \mathrm{Mo}$, and Co from dendrite to the interdendritic regions and $\mathrm{Al}, \mathrm{Ti}, \mathrm{Ta}$, and $\mathrm{Ni}$ in the opposite direction [15]. To simplify the diffusion process here, only the diffusion of Re is considered with two assumptions: the diffusion of Re is not affected by other alloy elements and is not permitted in the $\gamma^{\prime}$ phase.

Then considering the process of diffusion, the flux of matter or else can be given by the relation: Flux $=$ (conductivity) (driving force) [17]. In our case, the conductivity is the diffusivity of Re which is determined by temperature and the volume fraction of $\gamma$ phase according to the assumptions and the driving force is related to the concentration gradient of Re. On one hand, the conductivity of Re is better in the dendrite than that in the interdendritic region, since the volume fraction of the $\gamma$ phase is higher in the dendrite 


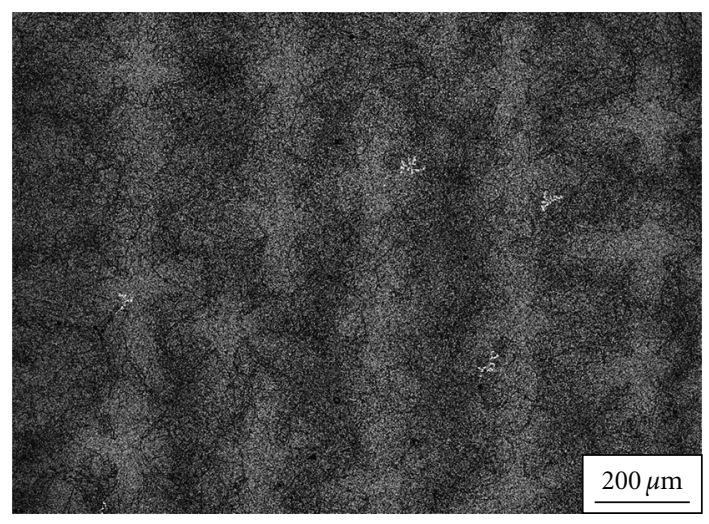

(a)

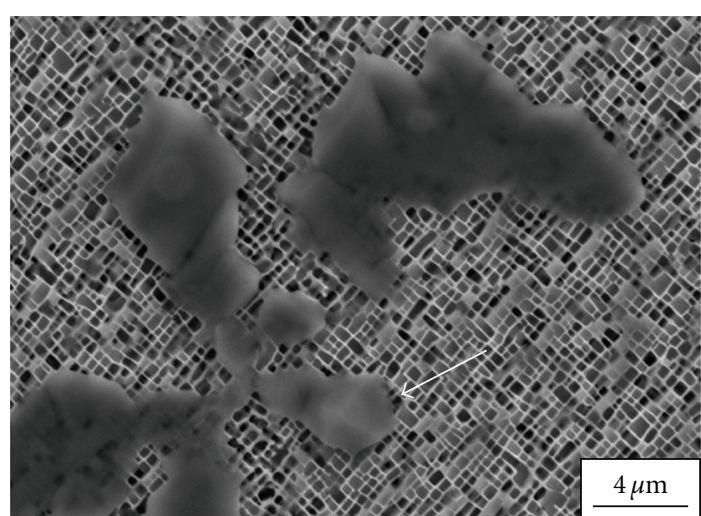

(b)

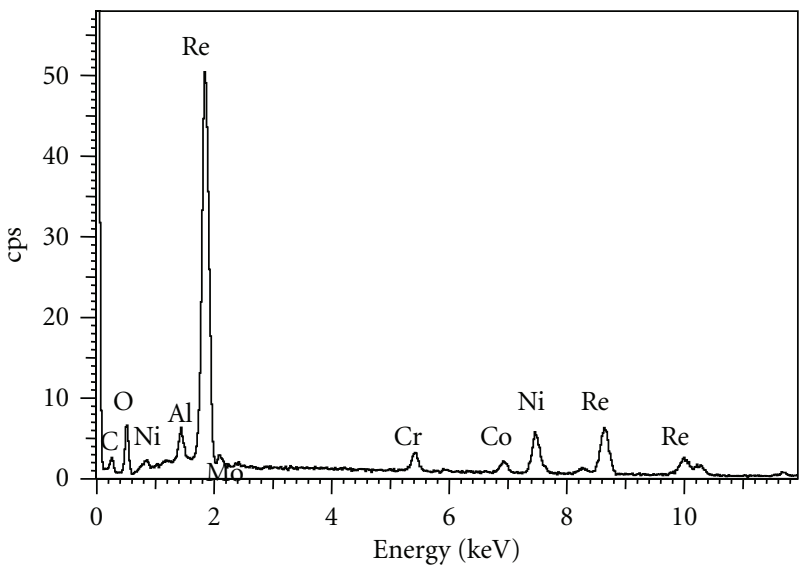

(c)

FIGURE 1: SEM micrographs and EDS analysis of the specimen after 800-hour thermal exposure: (a) BE image in low magnification, (b) SE image showing the detail of the Re-rich phase, and (c) EDS result of the faceted particle marked by the arrow in (b).

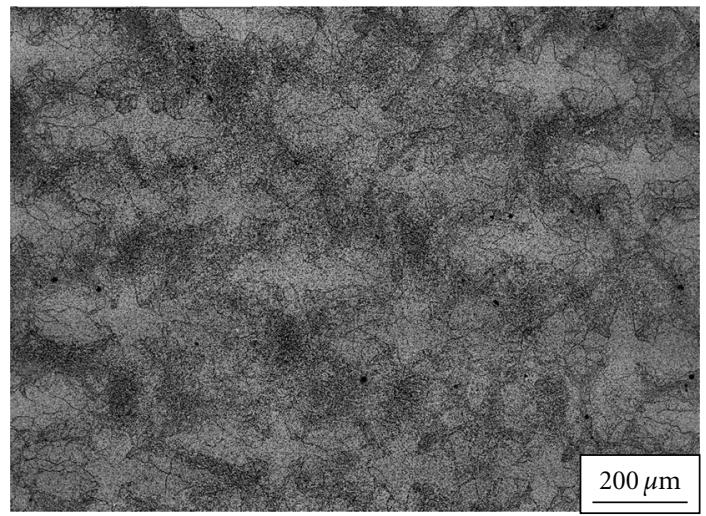

(a)

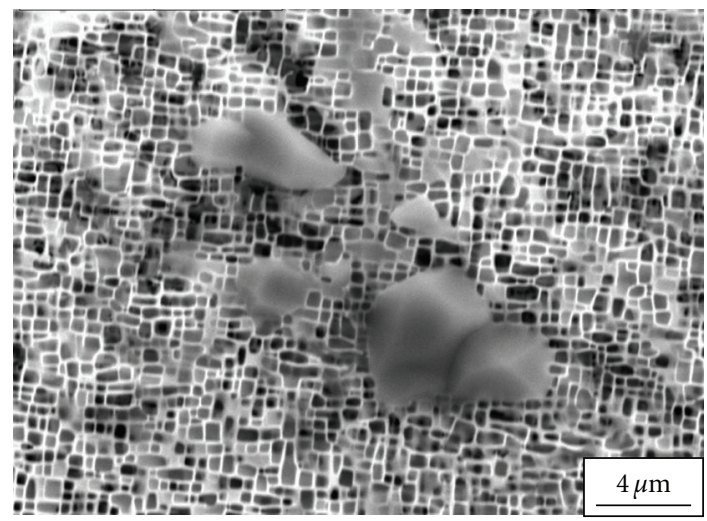

(b)

FIGURE 2: SEM micrographs of the specimen after 1000-hour thermal exposure: (a) BE image in low magnification, (b) SE image showing the detail of the Re-rich phase.

and the temperature is constant. On the other hand, it has proven in previous work [9] that the concentration along the line from dendrite core to interdendritic area of Re decreases smoothly, has a relative sharp decrease at the dendrite periphery, and then goes down smoothly again, which implies that the concentration gradient of Re is largest near the dendrite periphery between the dendrite core and the interdendritic region.

As a result, the flux exchange of Re would be relatively higher near the dendrite periphery and, at the same time, the Re might not diffuse away into the interdendritic region as fast as it diffused from the dendrite core to the dendrite 


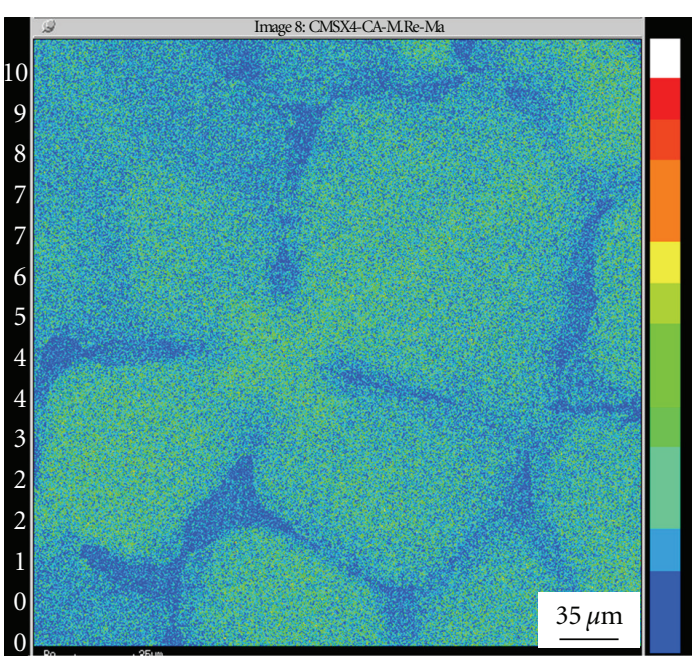

(a)

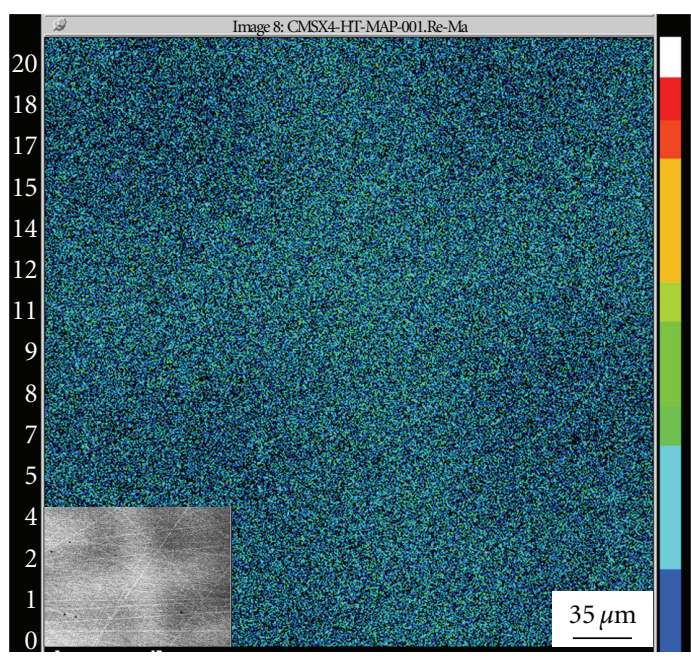

(b)

FIGURE 3: EPMA mapping analysis of Re: (a) as-cast condition, (b) after standard heat treatment with the inset showing the mapping area.

periphery. This may give rise to an accumulation of Re at the dendrite periphery. Moreover, the dendrite periphery might be taken as a pseudo-boundary where a new phase may readily form. Then, there might be a possibility to form the Re-rich phase from the matrix in this area. And with increasing the thermal exposure time, this phase gradually disappeared by diffusing away of the accumulated Re.

4.3. Significance of This Re-Rich Phase. As shown preciously, the amount of this Re-rich phase is extremely low in the specimen. Therefore, it could hardly affect the mechanical properties of the superalloy (Ph.D.). Importantly, the appearance of this Re-rich phase, even a little, may to some extent illustrate the particular behavior of Re in the superalloys. It may imply the preference of forming the Re-Re bond in the superalloys rather than forming Re-X bond (X means the other alloying elements), otherwise other compounds would form but the Re-rich phase. Lately, atom probe investigations of Re-containing superalloys have reported the clustering of Re in the $\gamma$ phase $[5,6]$, which could partly explain the obvious improvement of the Re addition to the superalloys [16]. The preference formation of the Re-Re bond may to some extent illustrate the formation of Re cluster in superalloys by means of short-range order of the Re atoms. It is tempted to say that the Rhenium atoms are prone to holding together locally rather than to being evenly distributed in the $\gamma$ matrix of superalloys.

\section{Conclusions}

In present study, a Re-rich phase (up to $85.40 \%$ wt. Re) was unexpectedly found in the single crystal superalloy CMSX4 after $800-1000$-hour exposure at $950^{\circ} \mathrm{C}$. It is surprisingly that this phase is located in front of the dendrite periphery in the interdendritic region, while the Re is segregated in the dendrite core but depleted in the interdendritic region. It was proposed that this Re-rich phase was caused by the unusual accumulation of the Re resulting from the uneven diffusion process of Re in the superalloys. Due to the scarce amount, it is incompetent to identify this Re-rich phase in this study. However, appearance of this Re-rich phase, even a little, may imply the preference of forming the Re-Re bond in the superalloys

\section{Acknowledgment}

This work was supported by the Korea Foundation for International Cooperation of Science and Technology (KICOS) through a grant provided by the Korean Ministry of Science and Technology (MOST) in K20711000001-07A010000110.

\section{References}

[1] T. Khan, P. Caron, and C. Duret, "The development and characterization of a high performance experimental single crystal superalloy," in Superalloys, M. Gell et al., Ed., pp. 145155, The Metallurgical Society of AIME, Warrendale, PA, USA, 1984.

[2] A. D. Cetel and D. N. Duhl, "Second-generation nickel-base single crystal superalloy," in Suoerallovs, D. N. Dun et al., Ed., pp. 235-244, The Metallurgical Society, Warrendale, PA, USA, 1988.

[3] A. F. Giamei and D. L. Anton, "Rhenium additions to a Ni-base superalloy: effects on microstructure," Metallurgical Transactions A, vol. 16, no. 11, pp. 1997-2005, 1985.

[4] H. Murakami, H. Harada, and H. K. D. H. Bhadeshia, "The location of atoms in Re- and V-containing multicomponent nickel-base single-crystal superalloys," Applied Surface Science, vol. 76-77, pp. 177-183, 1994.

[5] D. Blavette, P. Caron, and T. Khan, "An atom probe investigation of the role of rhenium additions in improving creep resistance of Ni-base superalloys," Scripta Metallurgica, vol. 20, no. 10, pp. 1395-1400, 1986.

[6] N. Wanderka and U. Glatzel, "Chemical composition measurements of a nickel-base superalloy by atom probe field ion 
microscopy," Materials Science and Engineering A, vol. 203, no. 1-2, pp. 69-74, 1995.

[7] H. Murakami, P. J. Warren, and H. Harada, "Atom-Probe Microanalysis of Some Ni-base Single Crystal Superalloys," in Proceedings of the 3rd International Charles Parsons Turbine Conference, p. 343, Institute of Materials, Newcastle-uponTyne, UK, April 1995.

[8] P. Druska, U. Steinike, and V. Sepelak, "Surface structure of mechanically activated and of mechanosynthesized zinc ferrite," Journal of Solid State Chemistry, vol. 146, no. 1, pp. 1321, 1999.

[9] K. Y. Cheng, C. Y. Jo, T. Jin, and Z. Q. Hu, "Effect of stress on $\mu$ phase formation in single crystal superalloys," Materials Science and Engineering A, vol. 528, no. 6, pp. 2704-2710, 2011.

[10] L. A. Cornish and M. J. Witcomb, "Metallographic study of the Al-Ni-Re phase diagram," Journal of Alloys and Compounds, vol. 291, no. 1-2, pp. 145-166, 1999.

[11] S. Miyazaki, Y. Murata, and M. Morinaga, "Site occupancy of Re atoms in $\operatorname{Ni3} \mathrm{Al}\left(\gamma^{\prime}\right)$ and $\gamma-\gamma^{\prime}$; phase equilibria in Ni-Al-Re ternary alloys," Tetsu-To-Hagane/Journal of the Iron and Steel Institute of Japan, vol. 80, no. 2, pp. 161-165, 1994.

[12] Q. Feng, T. K. Nandy, and T. M. Pollock, "The Re (Ru)-rich $\delta$-phase in Ru-containing superalloys," Materials Science and Engineering A, vol. 373, no. 1-2, pp. 239-249, 2004.

[13] Q. Feng, T. K. Nandy, S. Tin, and T. M. Pollock, "Solidification of high-refractory ruthenium-containing superalloys," Acta Materialia, vol. 51, no. 1, pp. 269-284, 2003.

[14] V. Sepelak, D. Schultze, F. Krumeich, U. Steinike, and K. D. Becker, "Mechanically induced cation redistribution in magnesium ferrite and its thermal stability," Solid State Ionics, vol. 141-142, pp. 677-682, 2001.

[15] B. S. Bokstein, A. I. Epishin, T. Link, V. A. Esin, A. O. Rodin, and I. L. Svetlov, "Model for the porosity growth in single-crystal nickel-base superalloys during homogenization," Scripta Materialia, vol. 57, no. 9, pp. 801-804, 2007.

[16] D. Blavette, P. Caron, and T. Khan, "Superalloys 1988," in Proceedings of the 6th International Symposium on Superalloys, Seven Springs, p. 305, TMS, Pennsylvania, Pa, USA, September 1988.

[17] R. Barrett Craig, D. Nix William, and S. Tetelman Alan, The Principles of Engineering Materials, Prenitice-Hall, New Jersey, NJ, USA, 1st edition, 1973. 

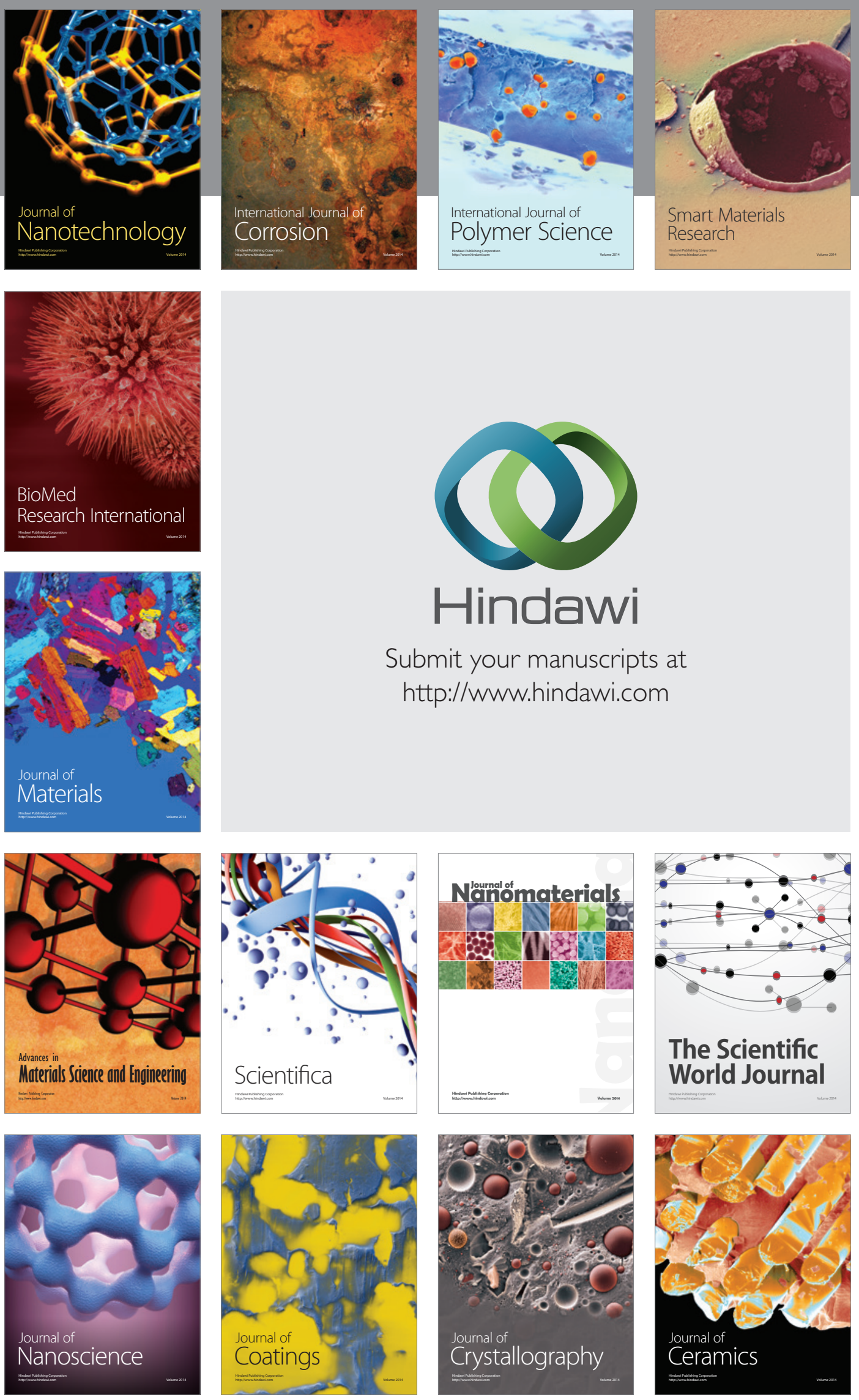

The Scientific World Journal

Submit your manuscripts at

http://www.hindawi.com

\section{World Journal}

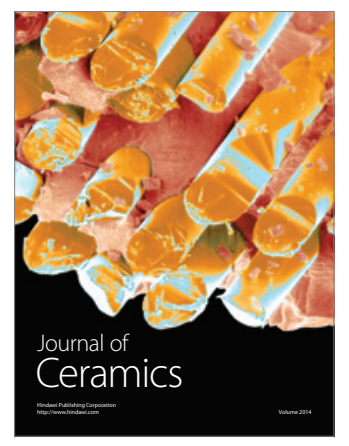

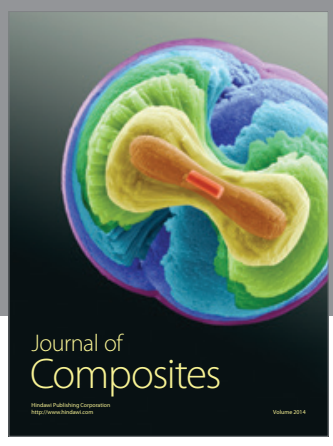
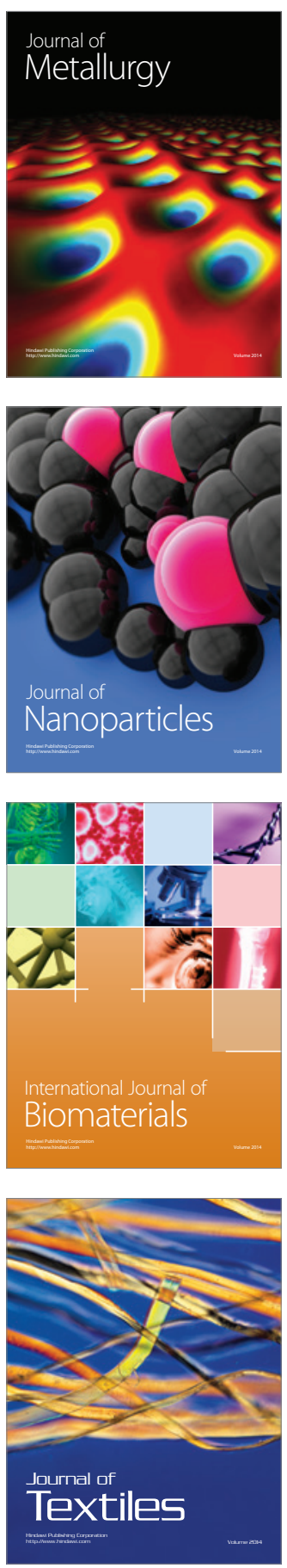